\title{
Mutual constraining of slow component and fast component measures: some observations in liver IVIM imaging
}

\author{
Yì Xiáng J. Wáng^ \\ Department of Imaging and Interventional Radiology, Faculty of Medicine, The Chinese University of Hong Kong, Hong Kong SAR, China \\ Correspondence to: Dr. Yì Xiáng J. Wáng. Department of Imaging and Interventional Radiology, Faculty of Medicine, The Chinese University of \\ Hong Kong, New Territories, Hong Kong SAR, China. Email: yixiang_wang@cuhk.edu.hk.
}

Submitted Feb 14, 2021. Accepted for publication Feb 24, 2021.

doi: 10.21037/qims-21-187

View this article at: http://dx.doi.org/10.21037/qims-21-187

Intravoxel incoherent motion (IVIM) theory in MRI was proposed by Le Bihan et al. in 1986 to account for the effect of vessel/capillary perfusion on the aggregate diffusion weighted MR signal. The fast component of diffusion is related to micro-perfusion, whereas the slow component is linked to molecular diffusion. Three parameters can be computed. $D_{\text {slow }}($ or $D)$ is the diffusion coefficient representing the slow 'pure' molecular diffusion (unaffected by perfusion). The perfusion fraction ( $f$ or $P F$ ) represents the fraction of the compartment related to (micro) circulation, which can be understood as the proportional 'incoherently flowing fluid' (i.e., blood) volume. $D_{\text {fust }}$ (or $D^{*}$ ) is the perfusion-related diffusion coefficient representing the incoherent microcirculation within the voxel, which holds information for blood perfusion's speed. The diffusion weighted image signal is prevalently modelled by a biexponential decay function [1]:

$$
\begin{aligned}
& S I_{(b)} / S I_{(0)}=(1-P F) \times \exp \left(-b \times D_{\text {slow }}\right) . \\
& +P F \times \exp \left(-b \times D_{\text {fast }}\right)
\end{aligned}
$$

where $S I_{(b)}$ and $S I_{(0)}$ denote the image signal intensity acquired with the $b$-factor value of $b$ and $b=0 \mathrm{~s} / \mathrm{mm}^{2}$, respectively.

In addition to intense research activities, a recent survey suggested IVIM has been applied in clinical practice in a small portion of institutions $(1,2)$.

Recently we reported that, for the liver, IVIM modeling of the perfusion component is constrained by the diffusion component, and a reduced $D_{\text {slow }}$ measure leads to artificially higher $P F$ and $D_{\text {fast }}$ measures (3). In this study of 26 male volunteers (age: 22-69 years) and 36 female volunteers (age: 20-71 years), we demonstrated an age-dependent liver $D_{\text {slow }}$ decline, which is expected to be caused by an agedependent iron deposition increase, an age-dependent fat deposition increase, and also a reduction of vasculature in the healthy aging livers. The age-dependent reduction in liver blood flow has been well documented using a variety of technical methods including histology, dye dilution, and indicator clearance (4-6). Using an MRI based microperfusion volume biomarker diffusion-derived vessel density (DDVD) $(7,8)$, we also observed age-dependent DDVD decline. However, the observed $P F$ and $D_{\text {fast }}$ results gave contradictory results compared with DDVD and known vessel physiology of the liver aging, with both $P F$ and $D_{\text {fast }}$ measures showed age-dependent elevation. This was observed when we used segmentation fitting or full fitting, and observed when we performed bi-exponential decay fitting included or excluded $b=0$ data (3). We concluded that the quantification of both $P F$ and $D_{\text {fast }}$ is constrained by $D_{\text {slow }}$, i.e., lower $D_{\text {slow }}$ leads to higher $P F$ and $D_{\text {fast }}$ measurements, even $P F$ and $D_{\text {fast }}$ did not increase or even declined. Our point is further supported by literature analysis that liver steatosis IVIM studies show a decreased $D_{\text {sloww }}$ and an artificially elevated $P F(9)$. Despite the limited sample size, in the brain, a reduction of $P F$ leads to an artificial elevation of $D_{\text {slow }}$ measure and an elevation of $P F$ leads to an artificial lowering of $D_{\text {slow }}$ measure is illustrated by the example of McKinstry et al. (10). By moderating arterial

\footnotetext{
^ ORCID: 0000-0001-5697-0717.
} 

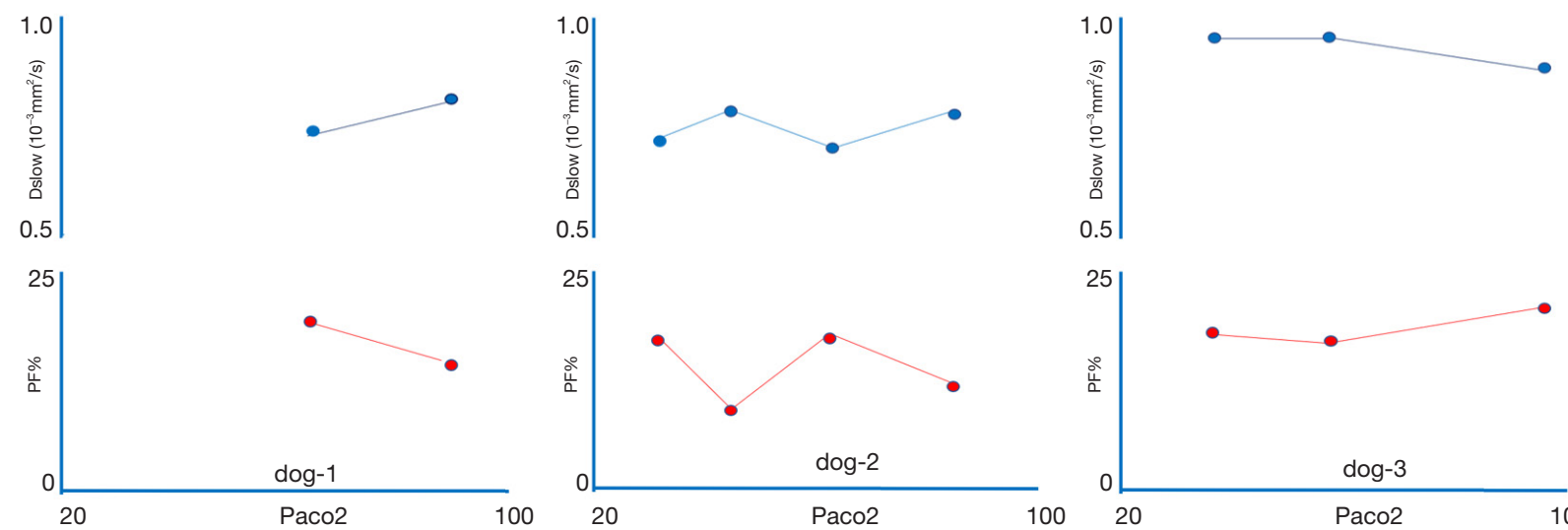

Figure 1 Variations in $D_{\text {slow }}$ and $P F$ following the changes of $\mathrm{PaCO}_{2}$. Under various $\mathrm{PaCO}_{2}, P F$ and $D_{\text {slow }}$ changed toward the opposition directions. In this study, segmented fitting was applied, and $P F$ is considered to change initially. $\mathrm{PaCO}_{2}$ : arterial carbon dioxide pressure (unit in torr). Adapted from reference (10).
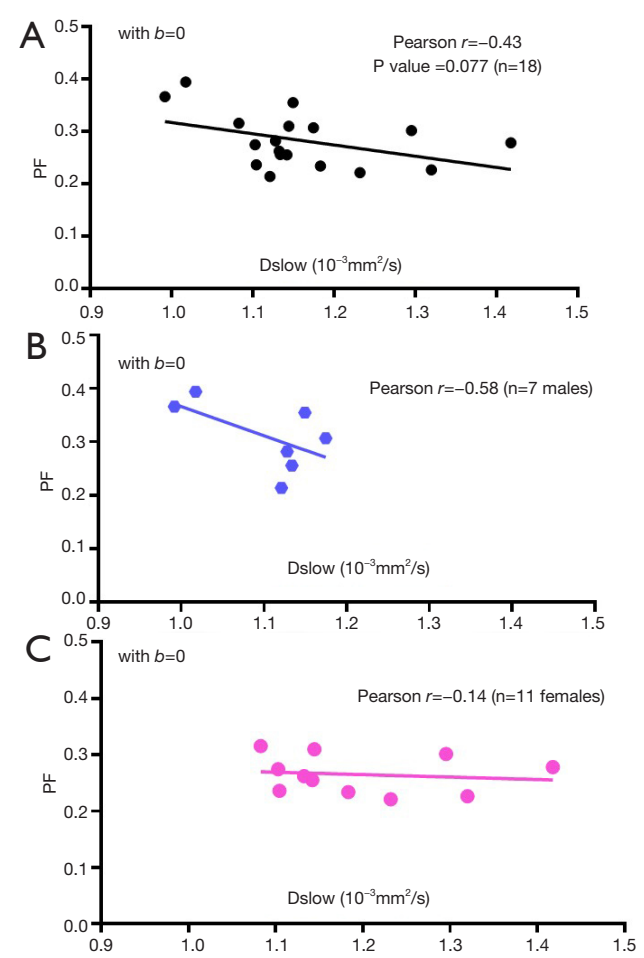

Figure 2 Measured correlations between $P F$ and $D_{\text {slow }}$ in 18 young healthy volunteers. The data are from reference (13). To only look at the measures of young subjects, two volunteers aged 38 yrs (male) and 58 yrs (female) respectively are not included. (A) data with biexponential fitting included $b=0$ data. (B) data for male subjects only. (C) data for female subjects only. Images were acquired at $3 \mathrm{~T}$ with $16 b$-values of $0,2,5,10,15,20,25,30,40,60,80,100,150$, 200,400 , and $600 \mathrm{~s} / \mathrm{mm}^{2}$, and analyzed by segmented fitting with threshold $b$-value of $60 \mathrm{~s} / \mathrm{mm}^{2}$. carbon dioxide pressure $\left(\mathrm{PaCO}_{2}\right), \mathrm{McKinstry}$ et al. (10) induced brain grey matter perfusion changes in three dogs. The results show, under various $\mathrm{PaCO}_{2}, P F$ and $D$ changed toward the opposition directions (Figure 1). This constrain is not absolute. For example, acute cerebral stroke can cause the reduction of all $P F, D_{\text {sloww }}$, and $D_{\text {fast }}$ in the ischemic core $(11,12)$, thus being all proportionally smaller. Overall, we observed that, according to the published IVIM data, if one component's measure, being that of perfusion component or diffusion component, changes toward one direction (i.e., increase or decrease), the other component's measure is constrained to change toward the opposite direction. In this letter, I discuss some clinical data of liver IVIM imaging which substantiate this observation, and postulate one of the possible causes for this paradox.

Figure 2 shows $P F$ and $D_{\text {slow }}$ measures in 18 young healthy volunteers (mean \pm SD: $24.1 \pm 3.2$ yrs; range, 18-31 years) (13). A moderate and close to statistically significant negative correlation is observed between $D_{\text {slow }}$ and PF (Figure $2 A$ ). If males and females subjects are separated, this negative correlation trend can be still observed (Figure 2B,C). In the study by Riexinger et al. (14) investigating the $1.5 \mathrm{~T}$ vs. $3 \mathrm{~T}$ field strength's effect on IVIM quantification with 20 healthy volunteers (age: 19-28 years) and an extensive array of $24 b$-values: $0.2,0.4,0.7,0.8,1.1,1.7,3,3.8,4.1$, $4.3,4.4,4.5,4.9,10,15,20,30,50,60,90,95,150,180$ and $500 \mathrm{~s} / \mathrm{mm}^{2}$, they reported liver $D_{\text {slow }}=1.22 / 1.00 \times 10^{-3} \mathrm{~mm}^{2} / \mathrm{s}$ at $1.5 / 3 \mathrm{~T}, P F=0.286 / 0.303$ at $1.5 / 3 \mathrm{~T}$, thus also showing $1.5 \mathrm{~T}$ scanner's results had higher $D_{\text {slow }}$ and lower $P F$, while 3.0T scanner's results had lower $D_{\text {slow }}$ and higher $P F$. It 
A

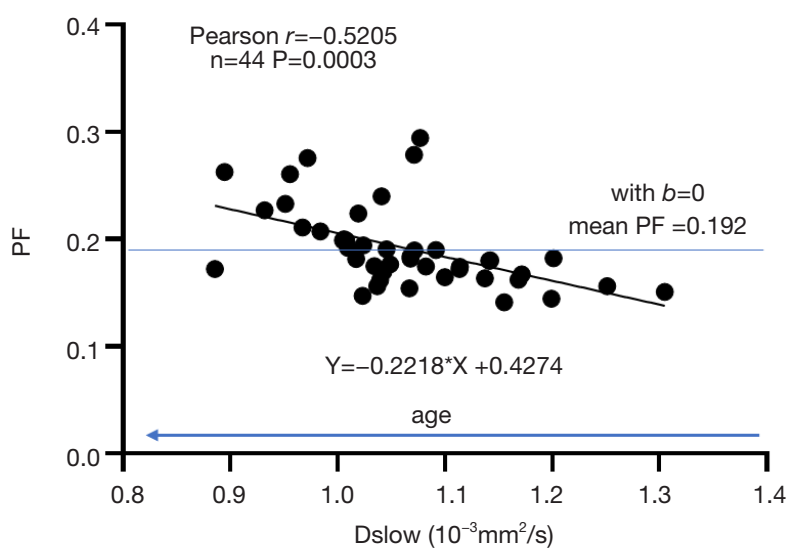

B

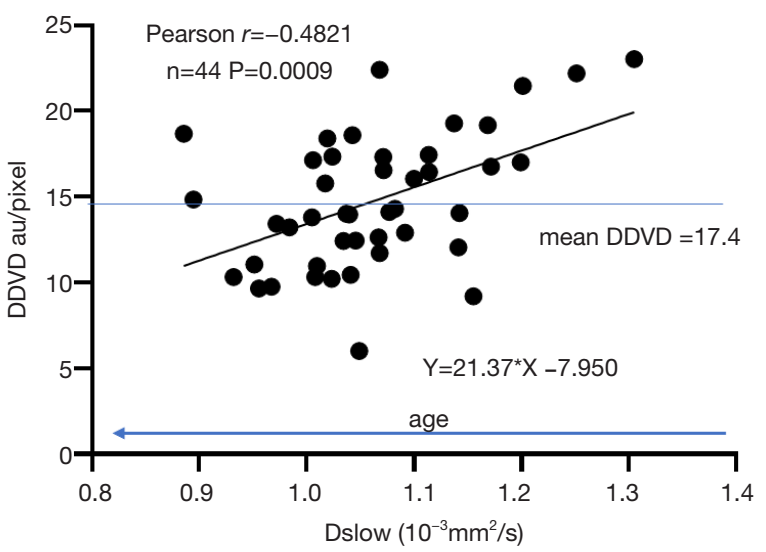

D

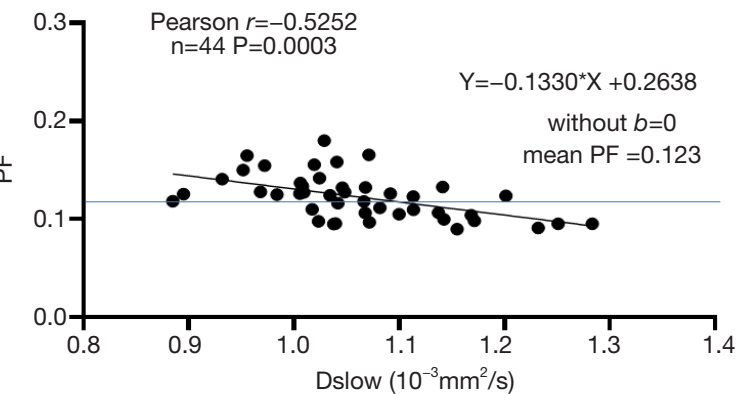

Figure 3 Approximate estimation of $D_{\text {slow }}$ induced $P F$ elevation. The data are from the study published in reference (3). The equations denote the linear fit of the data. (A) correlation between $D_{\text {slow }}$ and $P F$ computed included $b=0$ data. (B) correlation between $D_{s l o w}$ and DDVD. DDVD used here is the mean of $\operatorname{DDVD}(\mathrm{b} 0 \mathrm{~b} 2)$ and $\operatorname{DDVD}(\mathrm{b} 0 \mathrm{~b} 10)$. DDVD(b0b2) refers to the liver parenchyma signal difference between $b=0$ and $b=2 \mathrm{~s} / \mathrm{mm}^{2}$ images, with signal of visible vessels removed. DDVD(b0b10) refers to the liver parenchyma signal difference between $b=0$ and $b=10 \mathrm{~s} / \mathrm{mm}^{2}$ images, with signal of visible vessels removed. (C) illustration. Blue line-a2 assumes no change in $P F$ along aging, if so, a reduction of $D_{\text {slow }}$ along aging elevates line-a2 to line-a4. Line-a1 indicates actual reduction of perfusion along aging; in this case, a reduction of $D_{\text {slow }}$ along aging elevates line-a1 to line-a3. Line-a3 is thus the observed result, which is elevated by the magnitude of h1+h2. (D) correlation between $D_{\text {slow }}$ and $P F$ with $P F$ computed without $b=0$ data. au: arbitrary unit. DDVD, diffusion derived vessel density.

is possible that the results of Riexinger et al.'s study also suggests a trend of mutual constraining of diffusion measure and perfusion measure.

We can make a simplistic estimation on how much measured $P F$ can be artificially elevated if $D_{\text {slow }}$ is truly decreased by $10 \%$. We use the data from Huang et al.'s study (3), and we only choose those of very clean and good quality, i.e., those had two good quality IVIM scans and we were able to use the mean values from these two scans, which included 17 healthy men and 27 healthy women. We assume age of the subjects is the initial independent variable, and physiologically aging causes both $D_{\text {slow }}$ and $P F$ to decrease (3). We make a plot to study the relationship between $D_{\text {slow }}$ and PF (Figure $3 A$ ). We then assume $D_{\text {slow }}$ is the independent variable and $P F$ is the dependent variable.
The mean $D_{\text {slow }}$ is $1.06 \times 10^{-3} \mathrm{~mm}^{2} / \mathrm{s}$ in this study $\left(D_{\text {slow }}\right.$ value is the same for the analyses included or excluded $b=0$ data). If $P F$ is stable across different age groups (i.e., without aging interference), then a $10 \%$ reduction of $D_{\text {slow }}$ (i.e., a decrease of $\mathrm{X}$ in the linear fitting formula by 0.1 ) causes $11.6 \%$ artificial increase of $P F$ (i.e., an increase of $\mathrm{Y}$ in the linear fitting formula by 0.022 ). In the case here, $D_{\text {slow }}$ can also be considered as a surrogate of age, with older age associated with lower $D_{\text {slow }}$ value (3). In the study of Huang et al. (3), we used DDVD as a micro-perfusion volume biomarker, and demonstrated an aging related reduction of DDVD. Figure $3 B$ shows, a $10 \%$ reduction of $D_{\text {slow }}$ (i.e., a decrease of $\mathrm{X}$ in the linear fitting formula by 0.1 ) cause $12.3 \%$ reduction of micro-perfusion volume biomarker DDVD (i.e., a reduction of $\mathrm{Y}$ in the linear fitting formula by 2.14). For the 

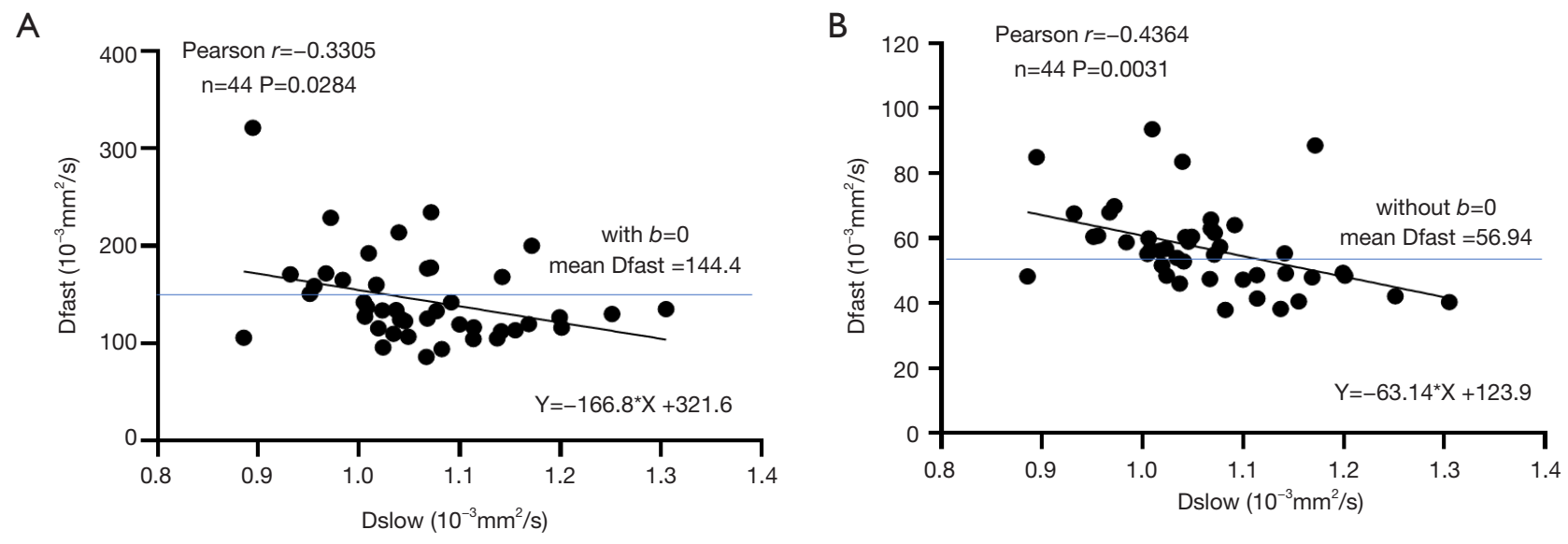

Figure 4 Estimation of observed $D_{\text {fast }}$ elevation following $D_{\text {slow }}$ reduction. The data are from the study published in reference (3). (A) contains values derived from analysis including $b=0$ data. (B) contains values derived from analysis excluding $b=0$ data. The equation denotes the linear fit of the data.

results seen in Figure $3 A$, it can be considered that, besides the apparent observed $P F$ reduction, the real $P F$ has already been additionally suppressed by the scale of $12.3 \%$ per $10 \%$ reduction of $D_{\text {slow }}$ due to aging. Thus, $10 \% D_{\text {slow }}$ decrease causes $23.9 \%(=11.6 \%+12.3 \%, 23.9 \%$ of the original $P F$ value) artificial increase of measured $P F$ (see Figure 3C). Figure $3 D$ shows IVIM analysis without $b=0$ data. In this case $(3 \mathrm{D})$, a $10 \%$ reduction of $D_{\text {slow }}$ (i.e., a decrease of $\mathrm{X}$ in the linear fitting formula by 0.1 ) causes $10.8 \%$ observed artificial increase of $P F$ (i.e., an increase of $\mathrm{Y}$ in the linear fitting formula by 0.013 ), which is similar to the result with $b=0$ data included in the analysis (Figure $3 A$ ). The same estimation can be made for the relationship between $D_{\text {slow }}$ and $D_{\text {fast }}$ (Figure 4). Figure $4 A$ shows, a $10 \%$ reduction of $D_{\text {slow }}$ (i.e., a decrease of $\mathrm{X}$ in the linear fitting formula by 0.1 ) causes $11.6 \%$ observed increase of $D_{\text {fast }}$ (i.e., an increase of $\mathrm{Y}$ in the linear fitting formula by 16.7). Figure $4 B$ shows, a $10 \%$ reduction of $D_{\text {slow }}$ (i.e., a decrease of $\mathrm{X}$ in the linear fitting formula by 0.1 ) causes $11.1 \%$ observed increase of $D_{\text {fast }}$ (i.e., an increase of $\mathrm{Y}$ in the linear fitting formula by 6.3). We consider $P F$ and DDVD are perfusion (blood) volume biomarkers, and $D_{\text {fast }}$ as a perfusion (blood flow) speed biomarker. Though smaller vessel diameters can hinder blood flow speed, it is more likely that, in the data of the study of Huang et al. (3), with aging blood flow speed did not change substantially, and the observed $D_{\text {fast }}$ elevation due to aging is more of an artifact due to the reduced $D_{\text {slow }}$. Guiu et al. (15) reported mean measured $D_{\text {slow }}$ values in steatotic livers $(\mathrm{n}=40)$ and nonsteatotic livers $(\mathrm{n}=68)$ were $1.03( \pm 0.23)$ and 1.24
$( \pm 0.15) \times 10^{-3} \mathrm{~mm}^{2} / \mathrm{s}$ respectively, while mean measured $P F$ values in steatotic livers and nonsteatotic livers were 0.33 $( \pm 0.09)$ and $0.27( \pm 0.09)$ respectively. From the Figure 3 in Guiu et al.'s study (15), we can assume their steatotic livers had on average $13 \%$ more fat content than the nonsteatotic livers, and if we assume pure fat tissue requires little perfusion (16), then according to the data of Guiu et al., a $10 \%$ reduction of $D_{\text {slow }}$ may lead to a $18 \% P F$ elevation. If the patients with steatotic livers were older than the patients with non-steatotic livers (which is likely to be true), then a $10 \%$ reduction of $D_{\text {slow }}$ may lead to $>18 \% P F$ elevation. Therefore, magnitude of $P F$ artificial elevation in the data of Guiu et al. seems to agree with our estimation for our own data. We reviewed the published results on IVIM-derived $P F$ of steatotic livers. Most of papers reported elevated $P F$ (9), a small portion of papers (17) reported $P F$ similar to normal liver which also indicate $P F$ was artificially elevated since steatotic livers should have reduced true $P F$.

In liver fibrosis, it is generally reported $P F$ is the most sensitive biomarker, $D_{\text {fast }}$ is more difficult to be qualified accurately $(18,19)$. Despite $D_{\text {slow }}$ can be measured with high reproducibility, it is considered being not sensitive to fibrotic change. Luciani et al. (20) compared 25 healthy liver cases and 12 cirrhotic liver cases with similar age and gender mixing, despite the patients had METAVIR score F4 liver cirrhosis, they obtained similar $D_{\text {slow }}$ values for healthy livers $\left[(1.10 \pm 0.7) \times 10^{-3} \mathrm{~mm}^{2} / \mathrm{s}\right]$ and cirrhotic livers $\left[(1.19 \pm 0.5) \times 10^{-3} \mathrm{~mm}^{2} / \mathrm{s}, \mathrm{P}>0.05\right]$. Our own published results also showed $D_{\text {slow }}$ values of METAVIR score F3-4 fibrotic 

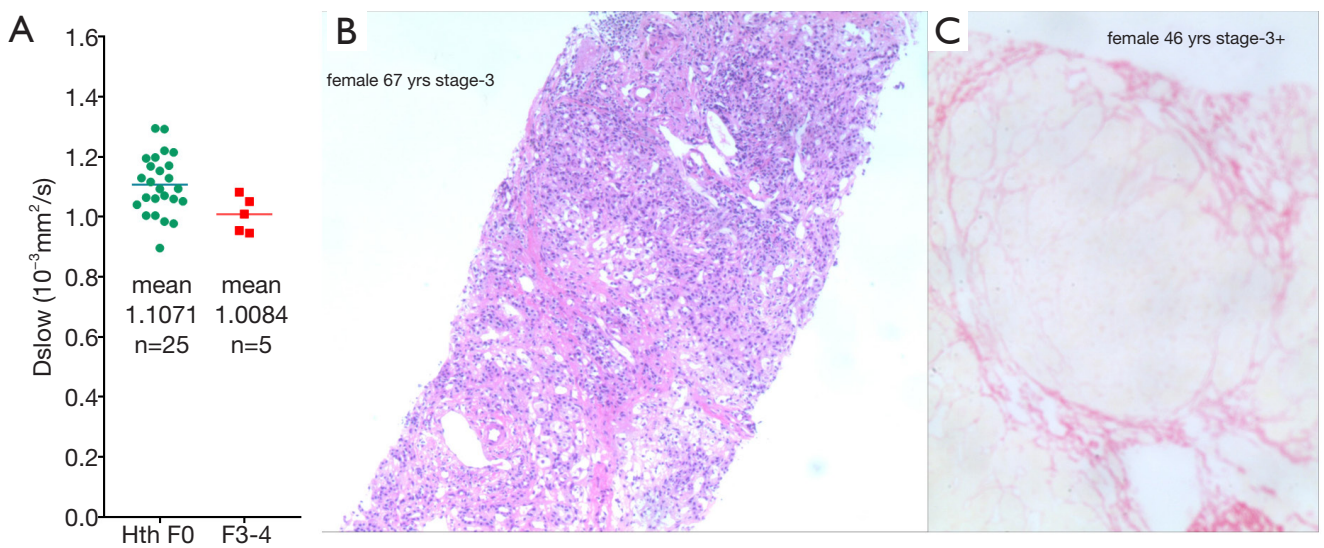

Figure 5 A comparison of $D_{\text {slow }}$ measure of young healthy livers (Hth-F0) and middle-aged/elderly subjects' stage-3/4 fibrotic livers (F3-4). Data are from reference (22). There are 25 young healthy subjects (mean age: 23.2 yrs, range: 20-29 yrs; 14 men males, 11 women), with one female volunteer of 41 yrs old not included. There are four stage-3 liver fibrosis patients (Male/59 yrs, Male/62 yrs, Female/46 yrs, Female/67 yrs) and one stage-4 liver fibrosis patient (Male/60 yrs). As the patients were older than the healthy subjects, the patients are expected to have lower liver $D_{\text {slow }}$ measure. (A) shows, though the mean $D_{\text {slow }}$ of the patients is lower than that of the healthy subjects, individually still the patient' values overlap with the normal $D_{\text {slow }}$ range. (B) is a histological image of a stage-3 fibrosis liver (HE staining, original magnification $\left.\times 100\right)$. (C) is a histological image of a stage-(3+) fibrosis liver (Sirius staining, original magnification $\times 100$ ). Considering the substantial structural changes of the stage-3, stage-4 fibrotic livers, it is unlikely the true $D_{\text {slow }}$ measure of these livers would be normal. We consider $D_{\text {slow }}$ measure was artificially promoted in these patients. Note that, we paid high attention to ensure the quality of data fitting for IVIM measures.

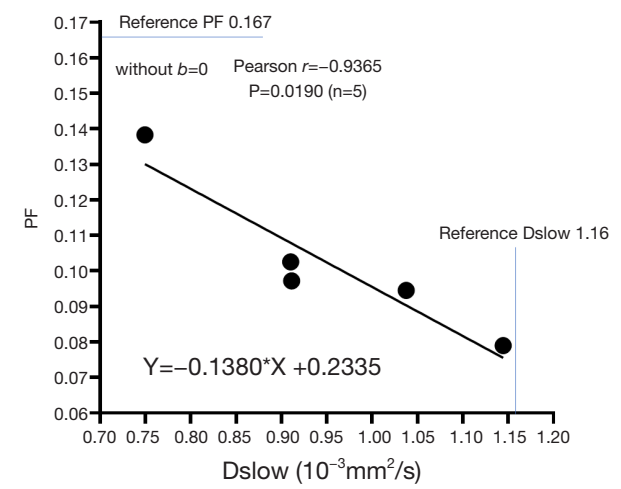

Figure 6 Relationship between $D_{\text {slow }}$ and PF in five stage-4 cirrhotic livers. Data are from reference (13). A very strong negative correlation is observed between $D_{\text {slow }}$ and $P F(r=-0.94)$. The equation denotes the linear fit of the five data points. The reference values are those of young healthy subjects. Data acquisition and analysis are the same as in Figure 7.

livers could overlap with those of the healthy young livers $(13,21,22)$ (Figure 5). This is puzzling considering the very substantial liver histopathological changes associated with cirrhosis. Figure 6 shows the mutual constraining of $D_{\text {slow }}$ measure and $P F$ measure in cirrhotic livers. We believe that $D_{\text {slow }}$ measure was promoted in fibrotic livers due to the decreased perfusion measure (Figure 7), published IVIM data are insensitive to slow diffusion restriction associated with fibrosis. In fact, since a true lowering of $D_{\text {slow }}$ can induce artificial elevation of $P F$, and a true lowering of $P F$ can induce artificial elevation of $D_{\text {slow }}$, it is possible for the published IVIM liver fibrosis studies, the magnitudes of reduction for $P F$ and $D_{\text {slow }}$ have been both underestimated.

Our analysis will have implications in interpreting IVIM data of other organs and pathologies as well. For example, in the cases of tumor characterization by IVIM, most malignant tumors have low diffusion (due to higher cellularity etc.), this will lead to their IVIM derived perfusion can 'always' be high as $P F$ is artificially promoted due to low $D_{\text {slow }}$. On the other hand, since malignant tumors tend to have high blood perfusion and therefore high $P F$, their $D_{\text {slow }}$ will be 'always' measured lower (the opposite to the scenario in liver fibrosis). However, the points discussed here do not necessarily disapprove the clinical usefulness of the current IVIM analysis approach. Examples (23-28), including those of our own $(13,21,22)$, demonstrated the value of IVIM metrics as useful approximations in some scenarios (but not in all scenarios). However, our analysis highlights the importance of a combined analysis of all 

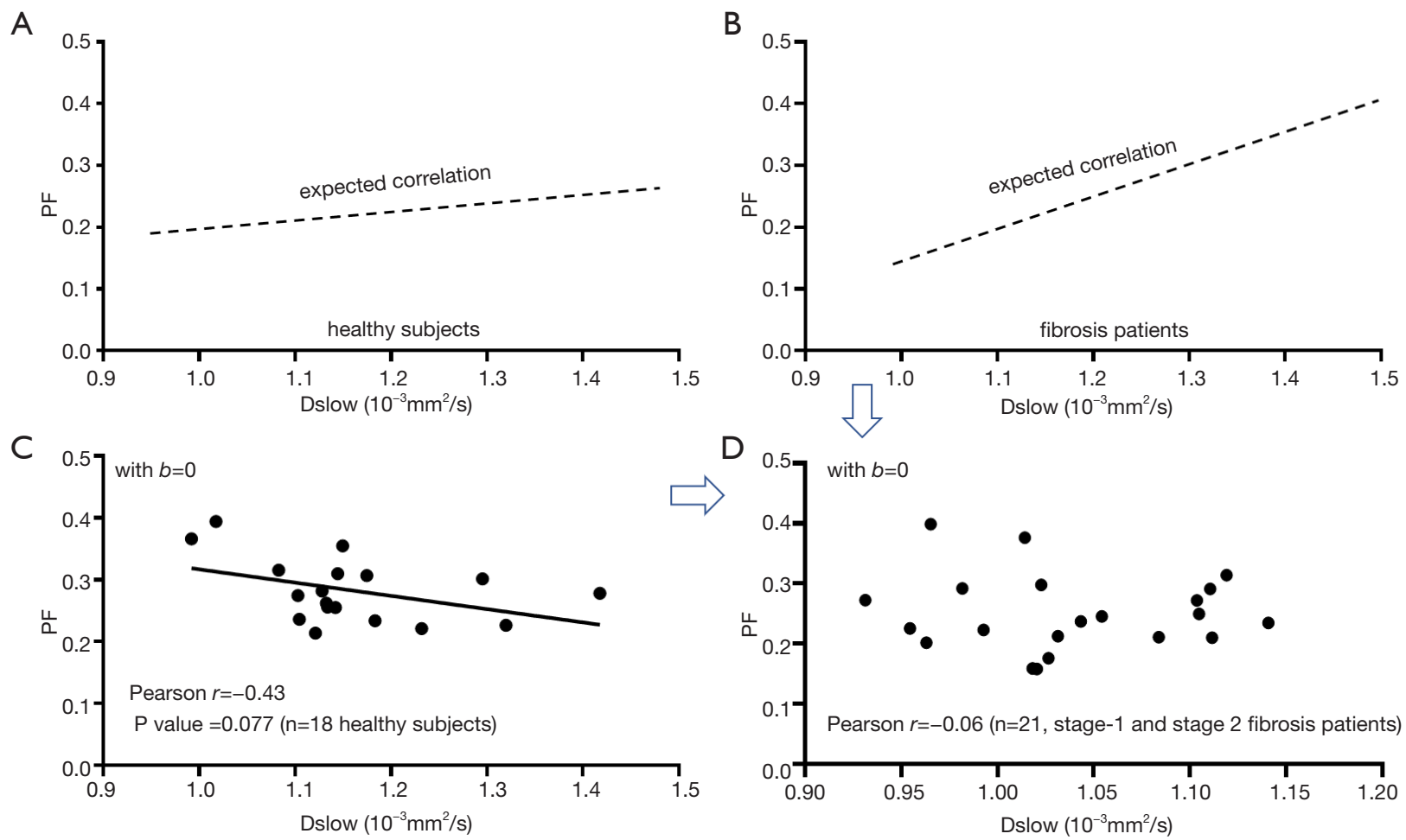

Figure 7 Expected and measured correlations between $\mathrm{PF}$ and $D_{\text {slow }}$. The measured data are from reference (13). Images were acquired at $3 \mathrm{~T}$ with $16 b$-values of $0,2,5,10,15,20,25,30,40,60,80,100,150,200,400$, and $600 \mathrm{~s} / \mathrm{mm}^{2}$, and analyzed by segmented fitting with threshold $b$-value of $60 \mathrm{~s} / \mathrm{mm}^{2}$. (A) Expected correlation between PF and $D_{\text {slow }}$ in healthy subjects. PF and $D_{\text {slow }}$ are weakly and positively correlated, due to perfusion's contribution to slow diffusion measurement. (B) Expected correlation between PF and $D_{\text {slow }}$ in patients. Due to perfusion's contribution to slow diffusion measurement and that more severe fibrotic changes would induce lower PF and $D_{\text {slow }}$ than those of milder fibrotic changes, thus PF and $D_{\text {slow }}$ are more positively correlated than that in (A). (C) Measured negative correlation between PF and $D_{\text {slow }}$ in healthy subjects (the same of Figure $2 A$ ). (D) Measured results of PF and $D_{\text {slow }}$ in 21 cases of stage-1 and stage-2 liver fibrosis patients ( $b=0$ data included for analysis). It can be explained that the interaction of the mechanism in (B) and the mechanism in (C) resulted in no correlation observed with the measured data in (D) for patients. The data suggest $D_{\text {slow }}$ measure might have been artificially promoted in these fibrotic livers in (D).

IVIM parameters $(8,21)$ and validating IVIM measures with other imaging or non-imaging measures. In the latter regard, many encouraging results, though not very strong correlation, have been reported. For example, Togao et al. (29) evaluated $P F$ in a comparison with histological immunostainted vascular density (\% Vessel) in 29 consecutive meningiomas. The 90 -percentile $P F$-value and average $P F$ in the tumor had significant correlations $(r=0.69, \mathrm{P}<0.0001 ; r=0.82, \mathrm{P}<0.0001)$ with the \% Vessel of the tumors. Lee et al. (30) reported 25 nude mice with HT29 colorectal cancer cells implantation had IVIM-MRI and histological micro-vessel density (MVD) assessment, Spearman's rank correlation with MVD was $0.782(\mathrm{P}<0.001)$ for $D_{\text {fast }}$, and $0.749(\mathrm{P}<0.001)$ for $P F$. Luo et al. (31) studied
35 male Sprague-Dawley rats induced with 106 cirrhosisrelated nodules and reported moderate negative correlations between $D_{\text {slow }}$ and cell density $(r=-0.624, \mathrm{P}<0.01)$. Wirestam et al. (32) correlated brain IVIM parameters with dynamic susceptibility-contrast MRI (cerebral blood volume and flow, CBV and CBF) in 28 volunteers. They demonstrated a moderate and significant correlation between $P F$ and CBV ( $r=0.56, \mathrm{P}<0.001)$. Federau et al. (33) acquired IVIM parameters in 21 brain gliomas, reported that $P F$ correlated moderately with dynamic susceptibility contrast relative CBV (r=0.59). Mayer et al. (34) studied IVIM and CT perfusion in 19 cases of pancreatic ductal adenocarcinoma, with the CT perfusion parameters blood flow (BF) and blood volume (BV) estimated. In ten patients, intra- 
tumoral MVD and microvessel area (MVA) were analyzed microscopically in resection specimens. For the tumors, $P F$ significantly positively correlated with BF $(r=0.668$, $\mathrm{P}=0.002)$ and $\mathrm{BV}(r=0.672, \mathrm{P}=0.002)$. There were significant positive correlations between $P F$ and MVD/MVA ( $r \geq 0.770$, $\mathrm{P} \leq 0.009)$. Correlation coefficients between $P F$ and MVD/ MVA were not significantly different from correlation coefficients between BF and MVD/MVA. On the other hand, imperfection correlation or no correlation have also been reported. For example, Patel et al. (35) assessed 30 subjects (16 with noncirrhotic liver, 14 with cirrhosis) with IVIM ( $\mathrm{n}=27)$ and DCE (dynamic contrast enhanced)-MRI $(n=20)$. They noted no correlation between IVIM and DCE-MRI parameters. Hectors et al. (36) studied 33 HCC lesions with IVIM and DCE-MRI and found no significant correlation between IVIM-DWI and DCE-MRI metrics in HCC lesions. They attribute this due to the predominant portal blood flow in the liver and tortuous microvasculature and tissue heterogeneity in HCC lesions.

High noise level can flatten the signal decay curve particularly at high $b$-values and lead to reduced $D_{\text {slow }}$ measure (7). We can intuitively postulate the observed mutual constraining of slow component and fast component measures may be partially related to the unavoidable image noises and data imperfection, particularly for echoplanar sequence-based diffusion weighted imaging and for liver imaging which is associated with physiological motions. If we fix the $b$-value for one $b$-image and assume $S I_{(0)}$ does not change, the equation-1 can be simplified to: $S I_{(b)}$ in left side of the equation as a dependant variable, $P F, D_{\text {slow }}$, and $D_{\text {fast }}$ as three independent variables in right side of the equation, and an increase of either one of three IVIM independent variables induces a decrease of $S I_{(b)}$. If $P F$ in the right side of the equation increases by 1 unit (the unit here has no physical meaning), we also assume the true $\mathrm{D}_{\text {slow }}$ and true $\mathrm{D}_{\text {fast }}$ do not change, then, following the increase of $P F$, predicted $S I_{(b)}$ in left side of the equation should decreases by 1 unit (the unit here has no physical meaning) accordingly so to maintain the validity of the equation. However, practically, due to image noises which do not change following the change of IVIM parameter, the measured $S I_{(b)}$ may decrease only 0.8 unit (as an example). To maintain the validity of the equation, either $D_{\text {slow }}$, or $D_{\text {fast }}$, or both $D_{\text {slow }}$ and $D_{\text {fast }}$ would artificially decrease (for example, both $\mathrm{D}_{\text {slow }}$ decrease 0.08 unit and $\mathrm{D}_{\text {fast }}$ decrease 0.08 unit respectively), and maybe the measured $P F$ increases only 0.96 unit. Thus, as observed in the study of Huang et al. (3), a true decrease of $D_{\text {slow }}$ induced artificial increase of measured $P F$ and measured $D_{\text {fast }}$. We expect there will be better agreement between the measured IVIM parameters and true IVIM parameters when noise level is low, and a better quantification of IVIM parameters should consider the image noises.

In pathologies, it is more likely that three IVIM parameters truly change simultaneously. In the ischemic core of an acute cerebral stroke, all $P F, D_{\text {slow }}$, and $D_{\text {fast }}$ have true reduction. In the case for liver fibrosis, a reduction of perfusion volume and $P F$ can be associated with smaller vessel diameters and more tortuous vessel paths, thus lower blood flow speed and lower $D_{\text {fast }}$. Further biological studies with animal models to compare noise compensated IVIM measures with other physiological measures will surely be useful. We expect stronger correlation between IVIM measure and other reference measures can be achieved by better IVIM modeling.

\section{Acknowledgments}

The author thanks Dr Hua Huang, staff radiologist at the Third People's Hospital of Shenzhen, Shenzhen, China; Dr Cun-Jing Zheng and Mr Xiao-Ben Heng, research students at the Chinese University of Hong Kong, Hong Kong SAR, for the supports.

Funding: None.

\section{Footnote}

Conflicts of Interest: The author has completed the ICMJE uniform disclosure form (available at http://dx.doi. org/10.21037/qims-21-187). Dr. XYJW serves as the Editorin-Chief of Quantitative Imaging in Medicine and Surgery.

Open Access Statement: This is an Open Access article distributed in accordance with the Creative Commons Attribution-NonCommercial-NoDerivs 4.0 International License (CC BY-NC-ND 4.0), which permits the noncommercial replication and distribution of the article with the strict proviso that no changes or edits are made and the original work is properly cited (including links to both the formal publication through the relevant DOI and the license). See: https://creativecommons.org/licenses/by-nc-nd/4.0/.

\section{References}

1. Manfrini E, Smits M, Thust S, Geiger S, Bendella Z, Petr J, Solymosi L, Keil VC. From research to clinical practice: 
a European neuroradiological survey on quantitative advanced MRI implementation. Eur Radiol 2021. [Epub ahead of print]. doi: 10.1007/s00330-020-07582-2.

2. Ljimani A, Caroli A, Laustsen C, Francis S, Mendichovszky IA, Bane O, Nery F, Sharma K, Pohlmann A, Dekkers IA, Vallee JP, Derlin K, Notohamiprodjo M, Lim RP, Palmucci S, Serai SD, Periquito J, Wang ZJ, Froeling M, Thoeny HC, Prasad P, Schneider M, Niendorf T, Pullens P, Sourbron S, Sigmund EE. Consensus-based technical recommendations for clinical translation of renal diffusionweighted MRI. MAGMA 2020;33:177-95.

3. Huang H, Zheng CJ, Wang LF, Che-Nordin N, Wang YX. Age and gender dependence of liver diffusion parameters and the possibility that intravoxel incoherent motion modeling of the perfusion component is constrained by the diffusion component. NMR Biomed 2021;34:e4449.

4. Zeeh J, Platt D. The aging liver: structural and functional changes and their consequences for drug treatment in old age. Gerontology 2002;48:121-7.

5. Wynne HA, Cope LH, Mutch E, Rawlins MD, Woodhouse KW, James OF. The effect of age upon liver volume and apparent liver blood flow in healthy man. Hepatology 1989;9:297-301.

6. Fiel MI, Deniz K, FElmali F, Schiano TD. Increasing Hepatic Arteriole Wall Thickness and Decreased Luminal Diameter Occur With Increasing Age in Normal Livers. J Hepatol 2011;55:582-6.

7. Wáng YX. Living tissue intravoxel incoherent motion (IVIM) diffusion MR analysis without $\mathrm{b}=0$ image: an example for liver fibrosis evaluation. Quant Imaging Med Surg 2019;9:127-33.

8. Xiao BH, Huang H, Wang LF, Qiu SW, Guo SW, Wang YX. Diffusion MRI Derived per Area Vessel Density as a Surrogate Biomarker for Detecting Viral Hepatitis B-Induced Liver Fibrosis: A Proof-of-Concept Study. SLAS Technol 2020;25:474-83.

9. Wáng YX. Observed paradoxical perfusion fraction elevation in steatotic liver: An example of intravoxel incoherent motion modeling of the perfusion component constrained by the diffusion component. NMR Biomed 2021. [Epub ahead of print]. doi: 10.1002/nbm.4488

10. McKinstry RC, Weiskoff RM, Belliveau JW, Vevea JM, Moore JB, Kwong KW, Halpern EF, Rosen BR. Ultrafast MR imaging of water mobility: animal models of altered cerebral perfusion. J Magn Reson Imaging 1992;2:377-84.

11. Federau C, Sumer S, Becce F, Maeder P, O'Brien K, Meuli $\mathrm{R}$, Wintermark $M$. Intravoxel incoherent motion perfusion imaging in acute stroke: initial clinical experience.
Neuroradiology 2014;56:629-35.

12. Zhu G, Federau C, Wintermark M, Chen H, Marcellus DG, Martin BW, Heit JJ. Comparison of MRI IVIM and MR perfusion imaging in acute ischemic stroke due to large vessel occlusion. Int J Stroke 2020;15:332-42.

13. Li T, Che-Nordin N, Wáng YXJ, Rong PF, Qiu SW, Zhang SW, Zhang P, Jiang YF, Chevallier O, Zhao F, Xiao XY, Wang W. Intravoxel incoherent motion derived liver perfusion/diffusion readouts can be reliable biomarker for the detection of viral hepatitis B induced liver fibrosis. Quant Imaging Med Surg 2019;9:371-85.

14. Riexinger AJ, Martin J, Rauh S, Wetscherek A, Pistel M, Kuder TA, Nagel AM, Uder M, Hensel B, Müller L, Laun FB. On the Field Strength Dependence of Bi- and Triexponential Intravoxel Incoherent Motion (IVIM) Parameters in the Liver. J Magn Reson Imaging 2019;50:1883-92.

15. Guiu B, Petit JM, Capitan V, Aho S, Masson D, Lefevre PH, Favelier S, Loffroy R, Vergès B, Hillon P, Krausé $\mathrm{D}$, Cercueil JP. Intravoxel incoherent motion diffusionweighted imaging in nonalcoholic fatty liver disease: a 3.0T MR study. Radiology 2012;265:96-103.

16. Ijaz S, Yang W, Winslet MC, Seifalian AM. Impairment of hepatic microcirculation in fatty liver. Microcirculation 2003;10:447-56.

17. Dijkstra H, Handayani A, Kappert P, Oudkerk M, Sijens PE. Clinical implications of non-steatotic hepatic fat fractions on quantitative diffusion-weighted imaging of the liver. PLoS One 2014;9:e87926.

18. Li Y', Cercueil JP, Yuan J, Chen W, Loffroy R, Wang YX. Liver intravoxel incoherent motion (IVIM) magnetic resonance imaging: a comprehensive review of published data on normal values and applications for fibrosis and tumor evaluation. Quant Imaging Med Surg 2017;7:59-78.

19. Zhang Q, Wang YX, Ma HT, Yuan J. Cramér-Rao bound for Intravoxel Incoherent Motion Diffusion Weighted Imaging fitting. Annu Int Conf IEEE Eng Med Biol Soc 2013;2013:511-4.

20. Luciani A, Vignaud A, Cavet M, Nhieu JT, Mallat A, Ruel L, Laurent A, Deux JF, Brugieres P, Rahmouni A. Liver cirrhosis: intravoxel incoherent motion MR imaging--pilot study. Radiology 2008;249:891-9.

21. Wáng YXJ, Deng M, Li YT, Huang H, Leung JCS, Chen W, Lu PX. A Combined Use of Intravoxel Incoherent Motion MRI Parameters Can Differentiate Early-Stage Hepatitis-b Fibrotic Livers from Healthy Livers. SLAS Technol 2018;23:259-68.

22. Huang H, Che-Nordin N, Wang LF, Xiao BH, Chevallier 
O, Yun YX, Guo SW, Wáng YXJ. High performance of intravoxel incoherent motion diffusion MRI in detecting viral hepatitis-b induced liver fibrosis. Ann Transl Med 2019;7:39.

23. Iima M, Le Bihan D. Clinical intravoxel incoherent motion and diffusion MR imaging: past, present, and future. Radiology 2016;278:13-32.

24. Szubert-Franczak AE, Naduk-Ostrowska M, Pasicz K, Podgórska J, Skrzyński W, Cieszanowski A. Intravoxel incoherent motion magnetic resonance imaging: basic principles and clinical applications. Pol J Radiol 2020;85:e624-35.

25. Paschoal AM, Leoni RF, Dos Santos AC, Paiva FF. Intravoxel incoherent motion MRI in neurological and cerebrovascular diseases. Neuroimage Clin 2018;20:705-14.

26. Federau C. Intravoxel incoherent motion MRI as a means to measure in vivo perfusion: A review of the evidence. NMR Biomed 2017;30:e3780.

27. Noij DP, Martens RM, Marcus JT, de Bree R, Leemans CR, Castelijns JA, de Jong MC, de Graaf P. Intravoxel incoherent motion magnetic resonance imaging in head and neck cancer: A systematic review of the diagnostic and prognostic value. Oral Oncol 2017;68:81-91.

28. Iima M, Honda M, Sigmund EE, Ohno Kishimoto A, Kataoka M, Togashi K. Diffusion MRI of the breast: Current status and future directions. J Magn Reson Imaging 2020;52:70-90.

29. Togao O, Hiwatashi A, Yamashita K, Kikuchi K, Momosaka D, Yoshimoto K, Kuga D, Mizoguchi M, Suzuki SO, Iwaki T, Van Cauteren M, Iihara K, Honda $H$. Measurement of the perfusion fraction in brain tumors with intravoxel incoherent motion MR imaging: validation with histopathological vascular density in meningiomas. $\mathrm{Br}$ J Radiol 2018;91:20170912.

30. Lee HJ, Rha SY, Chung YE, Shim HS, Kim YJ, Hur J, Hong YJ, Choi BW. Tumor perfusion-related parameter of diffusion-weighted magnetic resonance imaging:

Cite this article as: Wáng YXJ. Mutual constraining of slow component and fast component measures: some observations in liver IVIM imaging. Quant Imaging Med Surg 2021;11(6):28792887. doi: 10.21037/qims-21-187 correlation with histological microvessel density. Magn Reson Med 2014;71:1554-8.

31. Luo J, Zhou K, Zhang B, Luo N, Bian J. Intravoxel Incoherent Motion Diffusion-Weighted Imaging for Evaluation of the Cell Density and Angiogenesis of Cirrhosis-Related Nodules in an Experimental Rat Model: Comparison and Correlation With Dynamic ContrastEnhanced MRI. J Magn Reson Imaging 2020;51:812-23.

32. Wirestam R, Borg M, Brockstedt S, Lindgren A, Holtås S, Ståhlberg F. Perfusion-related parameters in intravoxel incoherent motion MR imaging compared with CBV and CBF measured by dynamic susceptibility-contrast MR technique. Acta Radiol 2001;42:123-8.

33. Federau C, Meuli R, O'Brien K, Maeder P, Hagmann P. Perfusion measurement in brain gliomas with intravoxel incoherent motion MRI. AJNR Am J Neuroradiol 2014;35:256-62.

34. Mayer P, Fritz F, Koell M, Skornitzke S, Bergmann F, Gaida MM, Hackert T, Maier-Hein K, Laun FB, Kauczor HU, Grenacher L, Klauß M, Stiller W. Assessment of tissue perfusion of pancreatic cancer as potential imaging biomarker by means of Intravoxel incoherent motion MRI and CT perfusion: correlation with histological microvessel density as ground truth. Cancer Imaging 2021;21:13.

35. Patel J, Sigmund EE, Rusinek H, Oei M, Babb JS, Taouli B. Diagnosis of cirrhosis with intravoxel incoherent motion diffusion MRI and dynamic contrast-enhanced MRI alone and in combination: preliminary experience. J Magn Reson Imaging 2010;31:589-600.

36. Hectors SJ, Wagner M, Besa C, Bane O, Dyvorne HA, Fiel MI, Zhu H, Donovan M, Taouli B. Intravoxel incoherent motion diffusion-weighted imaging of hepatocellular carcinoma: Is there a correlation with flow and perfusion metrics obtained with dynamic contrast-enhanced MRI? J Magn Reson Imaging 2016;44:856-64. 